\title{
Coping measures not enough to avoid loss and damage from drought in the North Bank Region of The Gambia
}

\author{
Sidat Yaffa \\ School of Agriculture and Environmental Sciences, \\ University of The Gambia, \\ Brikama Campus, West Coast Region, The Gambia \\ E-mail: syaffa@utg.edu.gm \\ E-mail: ksidat@netscape.net
}

\begin{abstract}
In 2011 the North Bank Region of The Gambia experienced its most severe drought in 20 years. This article looks at how this drought affected households in the region, the coping measures they adopted, and residual loss and damage. In this study, 'loss and damage' is defined as adverse effects of climatic stressors that people have not been able to avoid through coping and adaptation (from Warner et al., 2012). Data were collected through a questionnaire survey $(\mathrm{N}=373), 60$ focus group discussions and six expert interviews. Almost all respondents reported that the 2011 drought had affected their household, particularly through crop failure, livestock losses and high food prices. Most households tried to cope by seeking non-farm income or selling livestock to buy food. Others relied on food aid or social networks. However, for almost two thirds of the households, these measures were not sufficient or had adverse effects.
\end{abstract}

Keywords: loss and damage; global warming; drought; coping; households.

Reference to this paper should be made as follows: Yaffa, S. (2013) 'Coping measures not enough to avoid loss and damage from drought in the North Bank Region of The Gambia', Int. J. Global Warming, Vol. 5, No. 4, pp.467-482.

Biographical notes: Sidat Yaffa is an Assistant Professor of Agriculture at University of The Gambia, School of Agriculture and Environmental Sciences. $\mathrm{He}$ received his $\mathrm{BS}, \mathrm{MS}$ and $\mathrm{PhD}$ from the USA. His main research is built around climate change as it affects agricultural production. He is also the President/Chief Scientific Officer of a Gambian Agricultural/Environmental Consulting Company that he founded in 2010 . He also serves as the Lead Coordinator for the Least Developed Countries on Agriculture Negotiations at UNFCCC meetings. He has published three peer-reviewed papers and given several invited conference presentations. He received several awards for outstanding academic and community service work.

\section{Introduction}

\begin{abstract}
"Hunger started creeping into my family like an eagle scavenging for a carcass. I was most of the time agitated, especially when my wife asked me for food to cook each day. I felt like a destitute person in the street. Because of the drought and harvest failure, we had much less food to eat. We could no longer eat three times a day and we had to eat smaller portions. My health deteriorated and I
\end{abstract}


was most of the time feeling dizzy when standing. I went to the doctor who said that it was a result of not eating enough. Our situation became even worse when my two work cows and a donkey became very weak due to lack of forage. The poor rainfall of that year had affected the vegetation around the village where we graze our livestock. Almost all the grass was dry, and finding drinking water for the livestock was a challenge, as all the ponds had dried out. Because of the weak state of my work animals, I could not use them for long hours of work on the farm when the 2012 rains started setting in and when we had to prepare our fields. Because of that, the year after the drought, the harvest was also poor, even though the rains were okay."

This short account of drought impacts, described by Karamo Krubally of Malick Nana village, (Upper Niumi District), exemplifies the hardships that many households in the North Bank Region of The Gambia faced in 2011 when a severe drought hit. Although Karamo Krubally and many like him adopted coping measures to deal with drought impacts, they were not effective in averting adverse effects. This is an example of what has come to be known as 'loss and damage'.

Although there is no universally agreed definition of loss and damage, the following working definition has been used in this case study: loss and damage refers to negative effects of climate variability and climate change that people have not been able to cope with and/or adapt to Warner et al. (2012). The issue is much debated at international climate change conferences, where discussions have been taking place on the creation of an international mechanism to address loss and damage.

\subsection{Research objectives}

This paper reports on a case study that was part of a bigger project - the Loss and Damage in Vulnerable Countries Initiative, funded by the Climate and Development Knowledge Network (CDKN). The Institute of Environment and Human Security of the United Nations University (UNU-EHS) coordinated nine case studies (see Warner and van der Geest, 2013) that were conducted in vulnerable countries, one of which was The Gambia. The wider project has the following objectives:

a to improve understanding of how the interactions of climate variability and climate change with livelihoods (and other aspects of human well-being, such as health) and physical assets create particular patterns of loss and damage

b to start understanding how these factors might interact in coming decades as the impacts of climate variability and climate change are expected to manifest themselves more prominently

c to improve understanding of what combinations of policies can reduce loss and damage and increase resilience in the context of climate variability and climate change (Warner et al., 2012).

This paper focuses mainly on the first objective and, to a lesser extent, on the third (policy recommendations).

\subsection{Drought in The Gambia}

The Gambia is particularly prone to drought due to its location at the southern fringe of the Sahara desert. Total annual rainfall is highly variable and has been declining. Rainfall 
has been measured in the capital, Banjul, since 1886 (see Figure 1). Mean annual rainfall was approximately $1,200 \mathrm{~mm}$ between 1886 and 1969 , down to $883 \mathrm{~mm}$ in the $1970 \mathrm{~s}$, and $744 \mathrm{~mm}$ in the 1980s. In the 1990s and early 2000s, mean annual rainfall increased slightly, but was still less than $800 \mathrm{~mm}$. The downward trend is found not only in The Gambia. Throughout the Sahel, the 1970s and 1980s were much drier than previous decades (Dai et al., 2004; Dietz et al., 2004). The length of the rainy season decreased by an estimated 15 to 30 days across the country (Cessay et al., 1989). Virtually all agricultural land in the North Bank Region is rain-fed. This, and the fact that the majority of the population depends on agriculture for their livelihood, makes the region particularly vulnerable to climate variability and climate change.

Figure 1 Annual rainfall in Banjul (1886-2003) (see online version for colours)

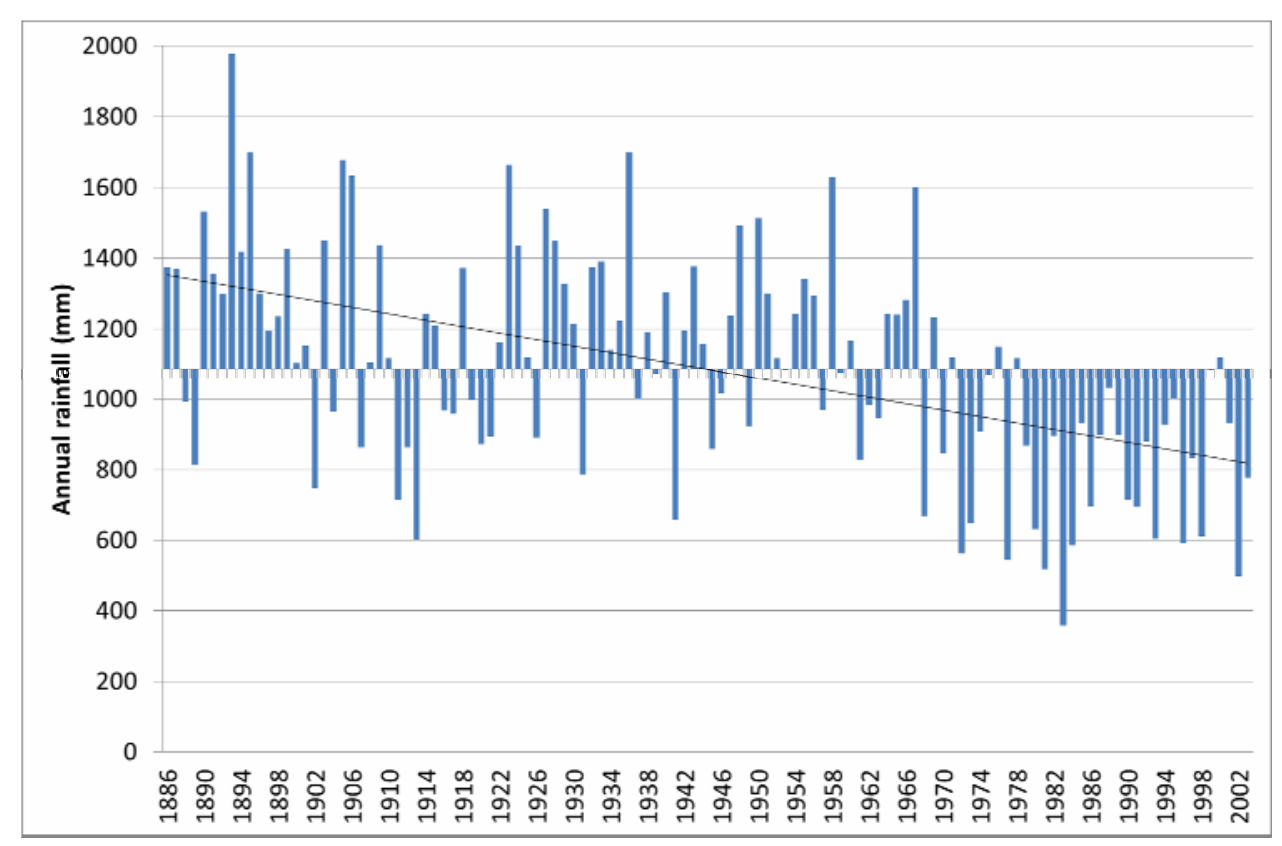

Source: Department of Water Resources, The Gambia Government

Long-term annual rainfall data for Kerewan, which is in the research study area (North Bank Region), is shown in Figure 2. Kerewan is slightly drier than Banjul; mean annual rainfall between 1931 and 2011 was $921 \mathrm{~mm}$. Just as in Banjul, annual rainfall has decreased sharply in the past decades (see Figure 2). The area experienced below-average rainfall in 29 out of the 40 years between 1972 and 2011. By contrast, this was the case in only 11 of the 40 previous years. Severe drought years, with less than $600 \mathrm{~mm}$ rainfall, were recorded in Kerewan in 1931, 1941, 1977, 1983, 1991 and 2011. The lowest rainfall was in 1983, with only $453 \mathrm{~mm}$. The 2011 drought, which is the focus of this paper, was the worst drought of the past 20 years, with total annual rainfall of $534 \mathrm{~mm}$. 
Figure 2 Annual rainfall in Kerewan (1931-2011) (see online version for colours)

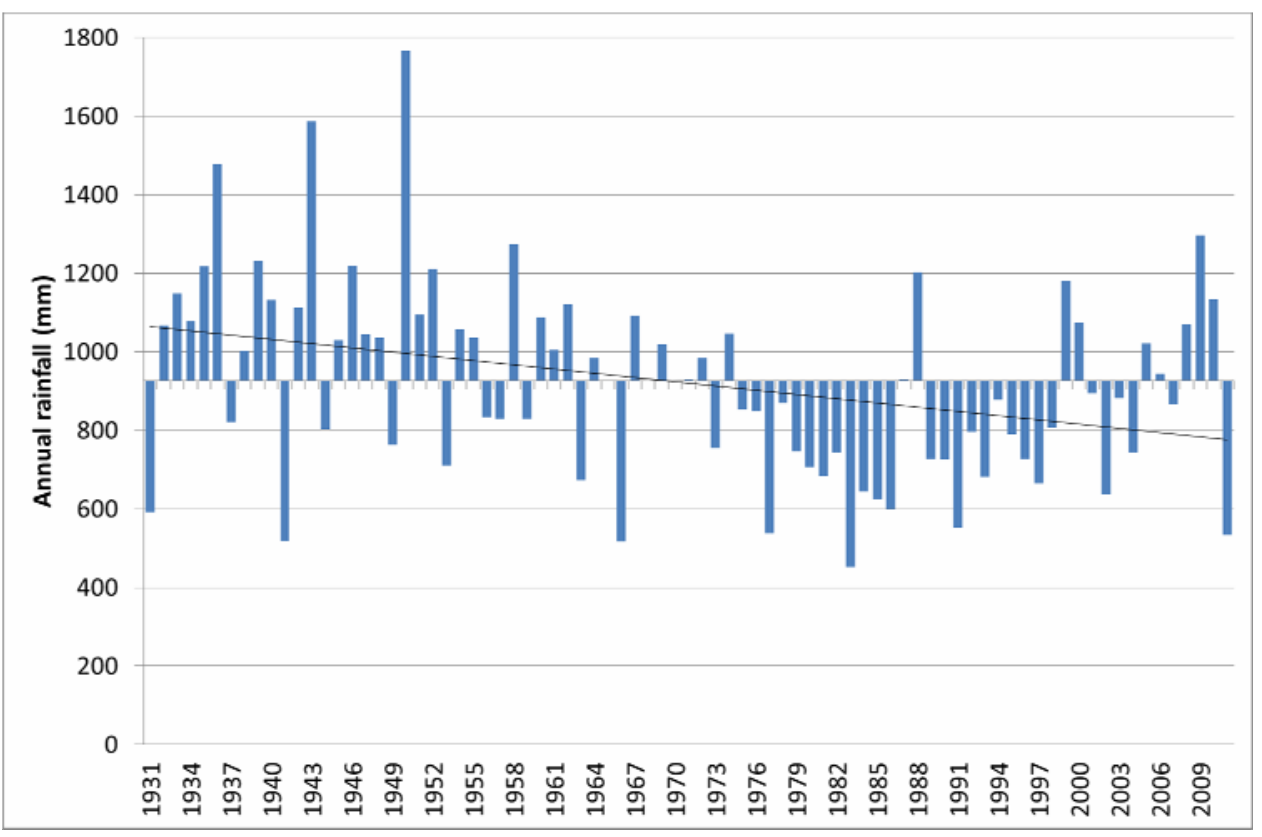

Notes: Missing data: 1965, 1968, 1970.

Source: Department of Water Resources, The Gambia Government

As well as understanding rainfall variation in The Gambia, it is important to know the onset, cessation and length of the crop growing seasons. This information is essential for planning agricultural activities, particularly sowing, to reduce the risk of total crop failure or having to replant. Farmers use various signs to predict the onset of rains (Gaye, 2004); the most popular are: the full sprouting of a particular baobab seedling, the arrival of the first heavy rain after 15 June (to determine the planting time for millet), and the arrival of the second heavy rain (to determine the planting time for groundnut and maize). In 2011, rains failed most significantly during the early part of the rainy season (June and July).

\subsection{Impacts of drought and coping strategies}

Low and poorly distributed rainfall, together with rising temperatures, reduces the productivity of crops such as corn, groundnuts and millet, and increases food insecurity, rural poverty and other hardships (Njie, 2007; Government of The Gambia, 2009; Boubacar, 2013). The Department of Agriculture (2005) estimated a $40 \%$ drop in groundnut yields due to rising temperatures. Njie (2007) developed a more complex model showing that food security projections for The Gambia are also to a large extent dependent on policy. Inter-annual variability of yields is shown to increase in the absence of compensatory management strategies.

The link between rainfall and crop production is not always straightforward. Zaal et al. (2004) calculated correlations between annual rainfall, annual drought risks and production figures for the most common crops in semi-arid West Africa. They found that yields are usually lower in dry years, but the link is less straightforward than they 
expected. The stage of growth during which a crop is exposed to drought or heat is critical. For example, when a crop is flowering or fruiting, it is extremely sensitive to changes in temperature and moisture. It is sometimes difficult to point to a cause-andeffect relationship between drought and crop production. There are other variables whose impacts on crop production may be difficult to isolate from those of drought. In The Gambia, those variables include pest and disease infestation, cropping intensity, declining soil fertility, and occasional difficulty in accessing farm inputs (Jallow et al., 1999).

Jallow et al. (1999) attempted to estimate losses in crop production during the (moderate) drought of 1990 . They found that the $27 \%$ fall below normal rainfall that year generated a $43 \%$ decline in groundnut production (55,000 metric tonnes), $10 \%(7,000$ metric tonnes) in coarse grains, and $28 \%$ (64,000 metric tonnes) for all other crops. In addition to the adverse effect of drought on crop yields, insufficient fresh water supply and pasture for livestock in drought years caused major constraints on livestock production, which is an important source of food and income in the region.

Although droughts are more frequent and severe now than before the 1970s, households in The Gambia have always had to cope with occasional droughts. There have been several government and non-governmental organisation (NGO) initiatives over many years aimed at minimising the adverse effects of drought (GTZ, 1999; National Environment Agency, 2004; Darboe and Bojang, 2005; Njie, 2007). Examples include afforestation, soil and water conservation techniques, promotion of vegetable cultivation in small irrigated gardens, and the introduction of drought-tolerant rice cultivars. Although some of these initiatives may have been successful in reducing vulnerability to drought, this paper shows that they were not enough to avoid loss and damage from the 2011 drought.

Very few studies have been conducted in The Gambia on household coping strategies in response to drought impacts. However, significant scholarly work in this field has been conducted in the wider Sahel region. This paper builds on early studies by Mortimore (1989) in Northern Nigeria; Davies (1996) in Mali, Devereux (1993) and van der Geest (2004) in Northern Ghana, and on several cross-country studies of drought impacts and coping in the Sahel (particularly Dietz et al., 2004). Many of these studies tend to emphasise that, despite poverty and underdevelopment, Sahelian farmers often have remarkably adaptable livelihoods, with important roles for migration, the spreading of risk in agriculture, and social networks. This study does not deny that, but goes a step beyond what people do when drought hits, by looking more critically at adverse effects that households experience despite - and resulting from - the coping measures they adopt.

\section{Methodology}

The case study was conducted in the North Bank Region of The Gambia. Thirty villages were randomly selected from a census list of all villages in the six districts of the region. In each village, two focus group discussions were organised, one with men and one with women. The study used qualitative methods (60 focus group discussions, six expert interviews and five open interviews with survey respondents) and quantitative methods (questionnaire survey, $\mathrm{N}=373$ ). The number of households selected per village depended on the population of the village and selection was random, using The Gambia 
government 2003 census data. The questionnaire had open-ended as well as closed-ended questions. As loss and damage is a new field of research, but builds on a long tradition of studying drought impacts and coping strategies, the closed-ended questions were used primarily to assess impacts and coping strategies, and the open-ended questions were used to explore the limitations and costs of coping strategies. The qualitative research tools were used primarily to gather information for which the questionnaire survey was less suitable. The methodology of this research project is described in more detail in Warner et al., 2012) and the questionnaire used is available at www.lossanddamage.net. This website also contains information about eight other case studies that used similar methods.

In this study, a distinction is made between two types of responses to climate stressors: 'coping' and 'adaptation'. These terms are often used synonymously. This is problematic because they involve different types of responses to different types of stressors (van der Geest, 2004; Birkmann, 2011). In this case study about loss and damage from drought in The Gambia, coping strategies are considered short-term responses, aimed at dealing with, or even surviving, the immediate impacts of droughts. Mostly, these measures involve actions undertaken to gain access to food when harvests have failed. When measures are beneficial in the short term and undermine livelihood sustainability in the future, they are labelled 'erosive coping' (de Waal, 1989; van der Geest and Dietz, 2004). 'Adaptation' was defined as being more lasting responses to more longer-term changes in rainfall patterns, for example livelihood diversification and agricultural change (e.g., adopting early-maturing cultivars).

The research strived to create a solid, empirical case study within the time and resource limits. The fieldwork was conducted in only one of The Gambia's six regions. The study covered approximately $2 \%$ of households in the North Bank Region. Although The Gambia is a small country, this case study should not be seen as a national assessment of loss and damage. Rather, it is a local case study that should be treated as a point of departure for further research.

\section{Study area}

The research area was in the North Bank Region, the region of The Gambia which is most vulnerable to drought due to low rainfall and patchy distribution of rainfall. The region also has less vegetative cover compared to the rest of the country (see Figure 3 and Gibba, 2002). Fieldwork took place in all six districts of the region. The North Bank Region is characterised by poor soil structure and fertility (Department of Agriculture, 2005). The region has become much more prone to drought in the course of the 20th century. This trend is similar to that of the Sahelian region as a whole, with relatively good rainfall until the late 1960s, severe droughts in the 1970s and early 1980s, and only partial recovery in the 1990s and 2000s (The Gambia Department of Water Resources, 2003; Dietz et al., 2004). Because of its low vegetative cover, the North Bank Region is highly susceptible to soil erosion during times of heavy rains and during windstorms in the dry season. Almost all the population of the region depend directly or indirectly on the agriculture sector. As a result, poor or failed harvests seriously threaten household food security and livelihoods. For example, low crop yields result in higher food prices, which, in turn, affect food availability and the amounts that households consume. 
Figure 3 Land use and villages surveyed in North Bank Region of The Gambia (see online version for colours)

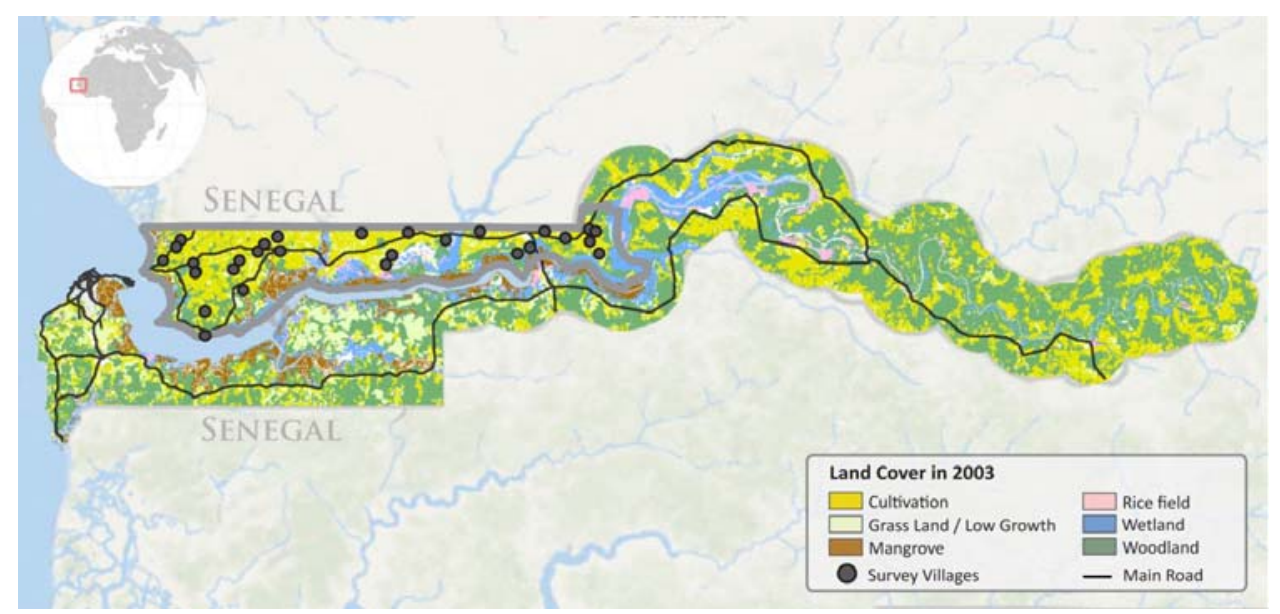

Source: Map created by the Center for International Earth Science Information Network (CIESIN)

\section{Results and discussion}

\subsection{Household characteristics}

The study surveyed 373 households, representing over $2 \%$ of the population of the North Bank Region. Household size was about 16 people and the average age of the respondents was 51 years. Of the households surveyed, $2.6 \%$ were headed by women. The majority of respondents were male household heads, but $14 \%$ were women who were either household heads or wives. The dependency ratio was 1.66, which means that on average, for every adult (aged 18-65) household member, there were 1.66 dependent household members (children or elderly). This was much higher than in the other research sites (see Warner et al., 2012).

Among heads of households, $16.5 \%$ had no formal education, $66.2 \%$ had Islamic education or a basic literacy course, $8.8 \%$ had attended only primary school, and $7.7 \%$ had secondary/tertiary education. The vast majority $(98.6 \%)$ of the surveyed household heads were Muslim.

The households studied were highly sensitive to drought because their livelihoods were based on crop cultivation (99.7\%) and livestock keeping (98.4\%). Despite high levels of engagement in crop production, access to good-quality land that could support household food consumption and income needs was a challenge in the study area. Although land ownership was high ( $97 \%$ of the households owned land), the area of land under cultivation was small for most households in the study area (median: 0.16 hectors per household member). According to the vast majority of respondents $(87.7 \%)$, their crop production had decreased over the past ten years, mainly because of poor rainfall, lack of money to buy farm inputs, lack of labour, and soil degradation.

For most households surveyed $(83.9 \%)$, crops were grown mainly for household consumption; $16.1 \%$ grew crops primarily to sell. The average household cash income in 
the study area was US\$621 per year. This is very low, especially considering the large household sizes. The proportion of income derived from crop sales was $30.7 \%$. Non-farm income (30.4\%), livestock sales (14.5\%) and remittances (13.4\%) were other important sources of income.

\subsection{Impact of the 2011 drought}

The 2011 drought affected almost all surveyed households in the North Bank Region (99.7\%). Most respondents (78.7\%) qualified impacts as 'severe' and $21 \%$ reported 'moderate' adverse effects of the drought. Only one respondent $(0.3 \%)$ said the drought had not affected him, because his household derived most of its income from salary work.

Of respondents who said the drought had had negative effects on their household economy, $98.1 \%$ reported impacts on crop production, $74 \%$ on livestock, $40.8 \%$ on tree crops and $9.4 \%$ on fishing activities (see Figure 4). The percentages for fishing and economic trees are lower partly because few households engaged in these activities compared to field crop cultivation and animal husbandry. In addition to the impacts on livelihood sources, $89.2 \%$ reported adverse effects on food prices. They thought the drought had led to higher food prices, which made it harder to cope by buying food when their harvests failed.

Figure 4 Proportion of households reporting different types of drought impacts (see online version for colours)

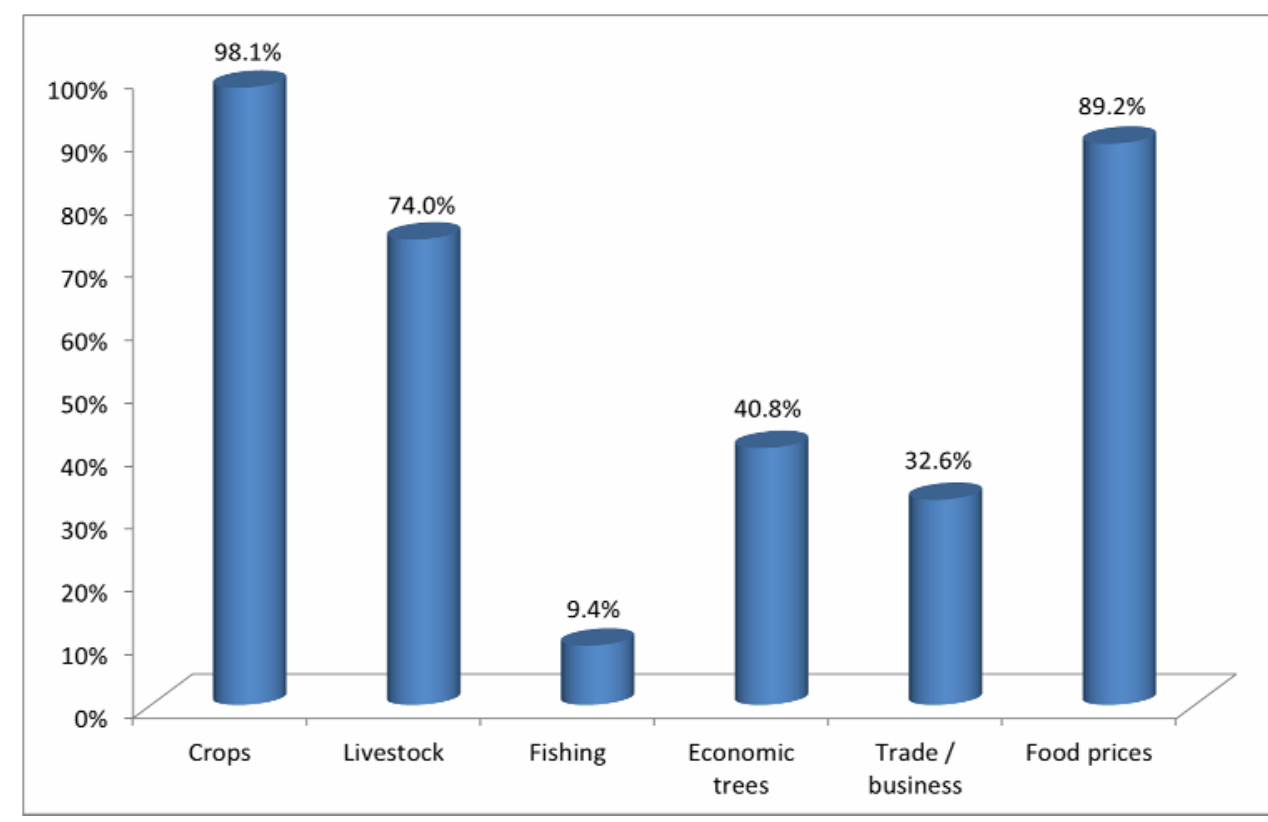

Source: The Gambia Loss and Damage questionnaire survey, July-August 2012

All of the six key experts interviewed reported that households in the region had been severely impacted by the drought in the sense that, as crop production was severely reduced, there were food shortages and high food prices. National crop production data 
confirm harvest failures for the four main food crops in the drought year 2011 (see Figure 5 and Table 1). Comparing production in 2011 to 2010, there was a decline of $39.1 \%$ for groundnut, $44.8 \%$ for maize, $64.2 \%$ for millet, and $48.8 \%$ for paddy rice (Table 1). The figures are high partly because 2010 was a good agricultural year. However, comparing the 2011 harvest with the average of five previous years, the production shortfall for millet $(47.5 \%)$, maize $(32.2 \%)$ and groundnut $(24.6 \%)$ is still very substantial.

Figure 5 Total national production (tonnes) of the four major food crops cultivated in the study area (see online version for colours)

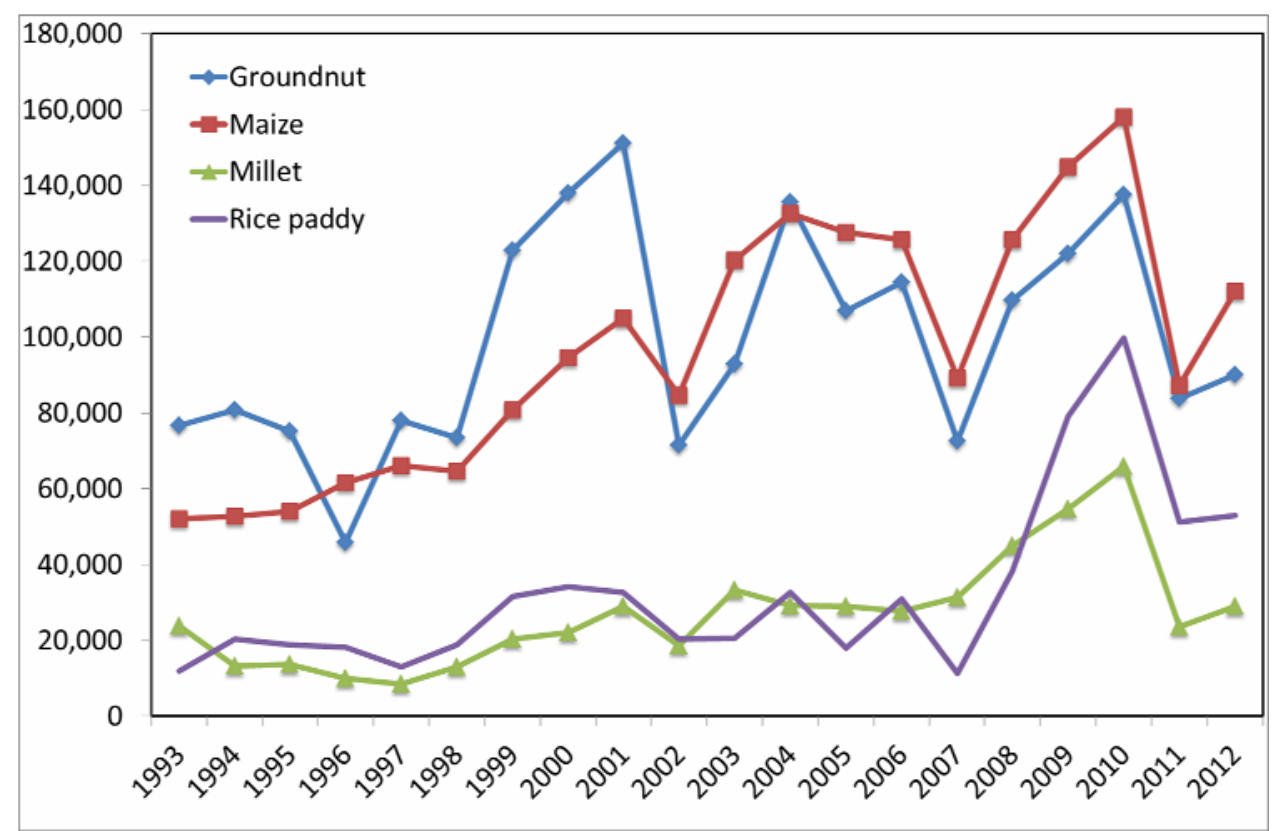

Source: FAO-STAT; data compilation and figure by van der Geest

Table 1 Decline in crop production after 2011 drought

\begin{tabular}{lcc}
\hline Crop & Decline from 2010 & Decline from 2006-2010 \\
\hline Groundnut & $39.1 \%$ & $24.6 \%$ \\
Maize & $44.8 \%$ & $32.2 \%$ \\
Millet & $64.2 \%$ & $47.5 \%$ \\
Rice paddy & $48.8 \%$ & $1.5 \%$ \\
\hline
\end{tabular}

Source: FAO-STAT

Evidence for increased food prices during and after the 2011 drought is less straightforward. Rice prices did increase substantially in the previous few years (see Figure 6). However, this can probably not be attributed to the 2011 drought, and the increase is less extreme when corrected for inflation. As much of the rice sold locally is imported, prices are influenced only to a limited extent by local production levels. One might expect a stronger drought signal in the price of millet, which is produced primarily 
in the North Bank Region, but no clear signal is discernible for millet prices either. But, as Figure 6 shows, the 2011 drought coincided with rising food prices, when expressed in the national currency, which added to the predicament of small-scale farmers in the region, many of whom had to find alternative sources of income with which to buy food when their crops failed.

Figure 6 Rice and millet prices (GMD/500 gr), based on six markets in NBR (2007-2012)

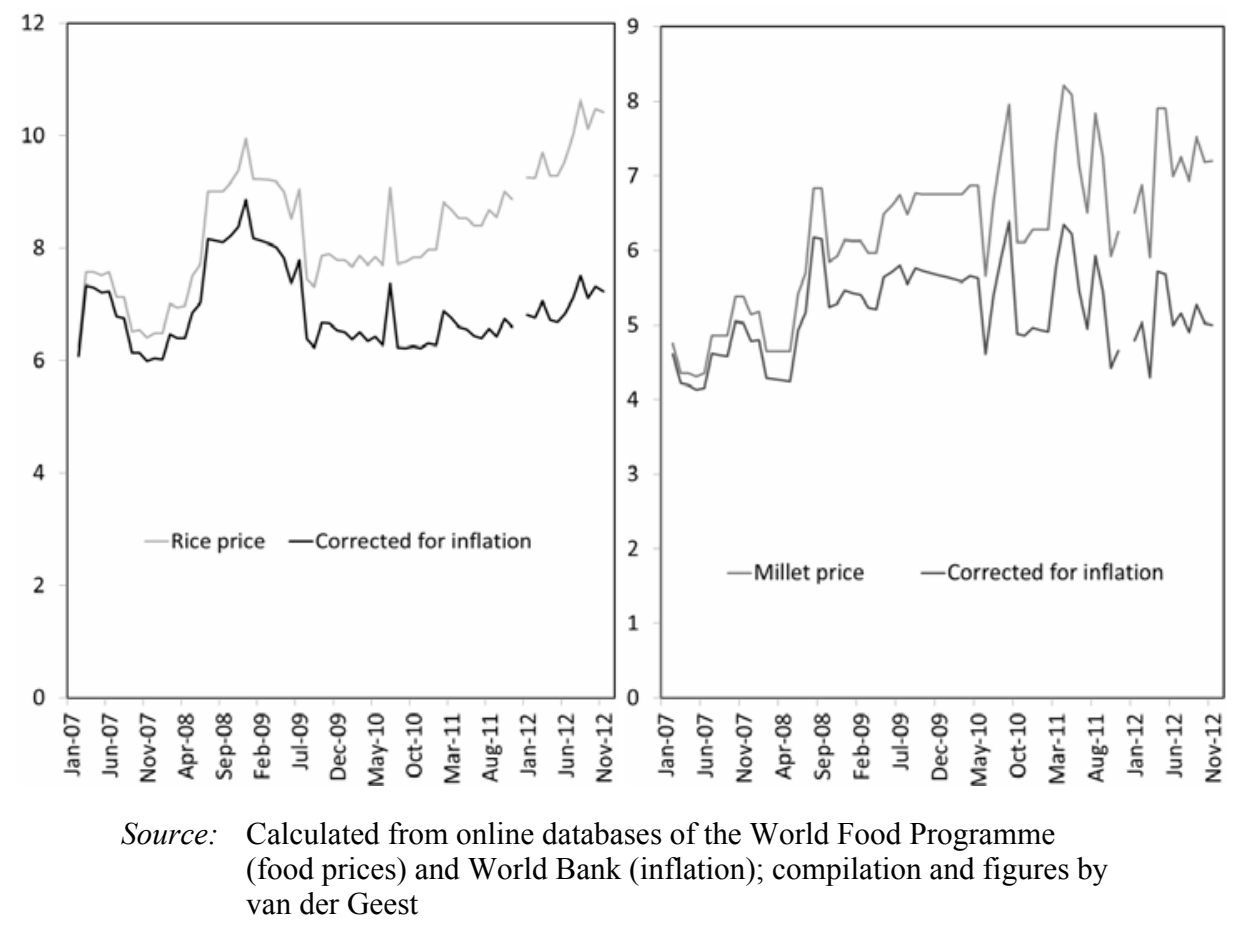

\subsection{Coping strategies and residual loss and damage}

To deal with the impacts of the 2011 drought, $94.9 \%$ of household respondents reported adopting at least one of the coping measures listed in Table 2. Coping strategies were primarily geared towards obtaining food after households lost some or all of their harvest. Table 2 shows the proportion of households that adopted different types of coping strategies. The most widely adopted coping strategy was to seek alternative incomegenerating activities when crops failed. More than half the surveyed households sold assets, particularly livestock, to buy food. Almost half further relied on social networks and support - mostly food aid - from the government and NGOs to deal with drought impacts. Temporary migration of household members to gain access to food or money to buy food was slightly less common, but still important for one out of four households. Table 2 also shows that almost two-thirds of respondents indicated that they cut down expenses to cope with the precarious situation that evolved after the 2011 drought, and another two-thirds had to reduce their food intake. In a way, these last two measures are also coping strategies, but at the same time, they are clear indications that other coping 
strategies have been inadequate. Below, the different coping strategies are described in more detail.

Table 2 Coping measures adopted to deal with impacts of the 2011 drought

\begin{tabular}{lcc}
\hline Measures adopted to cope with drought impacts & Households & $\begin{array}{c}\text { Proportion } \\
(N=371)\end{array}$ \\
\hline Rely on support from other people & 175 & $47 \%$ \\
Rely on support from organisations & 178 & $48 \%$ \\
Earn extra income to buy food & 257 & $69 \%$ \\
Migration of household members & 94 & $25 \%$ \\
Sell assets (e.g., livestock) to buy food & 205 & $55 \%$ \\
Other measures & 47 & $13 \%$ \\
\hline Measures that are a sign of inadequate coping capacity & & $64 \%$ \\
\hline Reduce food consumption after drought & 236 & $64 \%$ \\
\hline
\end{tabular}

Source: The Gambia Loss and Damage questionnaire survey, July-August 2012

\subsubsection{Reliance on food aid}

Almost half (48\%) the households surveyed in the North Bank Region received food aid from the government and NGOs in the aftermath of the 2011 drought. One could question whether receiving food aid should be considered a coping strategy. However, it became clear from talking with people in the area that receiving food aid required quite an active approach. Most households reported that aid came from the government, but the Gambia Red Cross Society and several other NGOs were also mentioned frequently. Food aid distribution was coordinated by the Office of the Governor (Chief Administrative Officer of the region). The amount of food aid received depended on the number of household members, but was usually two to three $50 \mathrm{~kg}$ bags of plain white rice. Food aid was distributed two to three times in the year throughout the region. For many households in the area, reliance on food aid from relief agencies was an important coping mechanism in the aftermath of the 2011 drought. However, the amount of aid they received was insufficient. Moreover, over half the households indicated that they did not receive any food aid at all. Therefore, most households had to adopt other coping strategies to obtain food.

\subsubsection{Seek extra income to buy food}

A very common way to deal with drought impacts in the North Bank Region of The Gambia is to engage in alternative income-generating activities to buy food when harvests fail. This strategy was adopted by more than two-thirds of the households surveyed. Such alternative activities could be new or unusual activities that people do not undertake in 'normal' years or existing activities that they intensify in times of scarcity. The most common activities were petty trade, horticulture, fishing, gathering firewood for sale, and construction work and other unskilled labour. Surprisingly, engaging in day labour on other people's farms was also a common coping strategy. One would expect 
that in a bad agricultural year, there would not be much demand for farm labour. The explanation is that wealthier farmers and traders in the community employed desperate household heads to work on their farm for food, or money to buy food, for their families. Although farm owners reap some direct benefit from doing this, it is mostly done out of sympathy with poorer households in the village, as part of long-term patron-client relations, and to affirm their status in the community.

\subsubsection{Sale of assets}

Over half (55\%) of the respondents reported selling assets to buy food when their harvests failed. Selling livestock was most common, but some also reported selling farm implements, such as horse carts and ploughs. Selling livestock to buy food is a very common and age-old coping strategy across Africa and elsewhere in the world where farmers combine crop cultivation and animal husbandry. However, it reduces people's asset base and buffer capacity, and they tend to get low prices for their animals if other farm households are also trying to sell livestock at the same time. This leaves people more vulnerable when rains fail again in the next cultivation cycle. The situation is worse when people have to sell their draught animals, such as bullocks, to offset the negative impacts of drought. This reduces their capacity to cultivate and harvest enough food to eat, irrespective of rainfall conditions. This kind of coping can be erosive in that it threatens the future sustainability of livelihoods and keeps households in a vicious cycle of poverty and coping.

\subsubsection{Reliance on social networks}

Almost half (47\%) of the household respondents relied on social networks either for food or for money to buy food. Most of them (91\%) sought support from relatives, many of who lived in urban areas. Social support networks were not confined to relatives. About a third (34\%) of those receiving support relied also on neighbours and $29 \%$ sought support from friends. In some communities in the survey area, heads of households and community leaders formed associations to help families with food or money in times of need. This support was usually provided as 'loans', which had to be paid back to the association after the next harvest. Relying on such locally created food banks can be embarrassing for household heads, as it shows they are unable to provide for their dependants in times of scarcity - but many had no choice.

\subsubsection{Migration}

Temporary migration of household members, mostly to urban centres, was used by $25 \%$ of the households surveyed to deal with drought impacts. Migration works in two ways: it reduces pressure on food stores, leaving more food for those who stay at home, and migrant household members will try to return with some savings to buy food for the family. In most cases, these 'hunger trips' were carried out by sons or younger brothers of the household head, and the main destination was the capital, Banjul, and the West Coastal Region. In 19 households, migrants had international destinations, mostly Senegal. Migrants mostly engaged in blue-collar work, for example as night watchmen or 
in construction. Although this coping measure can be successful in the short term, group discussions held in the survey villages revealed important social and health ramifications. Most of the household members who are sent away to earn money are young men. They often do not return to the village if they are embarrassed because their mission has failed; if they become used to city life and want to become independent there; or if they no longer want to work on the family farm. As these young men usually are the main source of farm labour for households, losing a son to the city can have serious consequences for household food security. Participants in focus group discussions also reported that young migrant men sometimes become sexually active in the urban centres and may contract sexually transmitted diseases, such HIV/AIDS. If they return home, they are likely to infect their wives, which leads to health problems for the concerned households.

\subsubsection{Reduce expenses}

Sixty-five percent of the households reported that they had to reduce expenses to buy grains. In a way this is also a coping measure, but at the same time it is a sign that other coping strategies have failed, especially if people have to cut expenses that are necessary for their survival and development. The majority of the households that cut expenses (77\%) economised on non-essential food items such as salt, meat, vegetables, coffee and sugar, and some mentioned spending less on cigarettes and clothing. This does not threaten the survival or sustainability of their livelihood. However, almost a third (30.8\%) had to save money on educating their children, for example by taking a child out of school, and almost a quarter (23.7\%) had to economise on health expenses, which can have serious implications. Other examples of coping include young men putting off marriage proposals in order to buy food for their families, and mothers cancelling plans to buy cooking utensils for daughters who were likely to move away upon marriage. These marriage plan cancellations have negative effects on the social fabric of the community.

\subsubsection{Modify food consumption}

Another sign of failing coping strategies is that $64 \%$ of the households surveyed had to modify food consumption to deal with drought-induced harvest losses. This could involve buying cheaper, less nutritious food, reducing the number of meals per day, limiting portion sizes, adults eating less to leave enough food for children and pregnant wives, or a combination of these measures. This can cause serious health and physical and mental development problems, especially for young children. In addition, hunger reached its peak in June, July and August, the months prior to the next harvest when households have to work hard on the farm to secure enough food for the following year. With stomachs only half-filled, the strength and productivity of farm workers was seriously constrained.

Of the households that adopted coping strategies to deal with drought impacts, $63 \%$ said these measures had not been enough to offset the negative impacts of the 2011 drought (Table 3). This is roughly the same as the proportion of households that had to modify food consumption. 
Table 3 Effectiveness of coping measures

\begin{tabular}{lc}
\hline Were coping measures enough to avoid negative effects? & Percentage of households \\
\hline No, still severe negative effects & $39 \%$ \\
No, still moderate negative effects & $24 \%$ \\
Yes, it enabled us to 'return to normal' & $34 \%$ \\
Yes, the situation even improved & $2 \%$ \\
\hline
\end{tabular}

Source: The Gambia Loss and Damage questionnaire survey, July-August 2012

\section{Conclusions and recommendations}

Based on fieldwork in nine countries, of which The Gambia case study discussed in this paper was one, Warner and van der Geest (2013) identified four loss and damage pathways. Households in vulnerable communities incur loss and damage when:

1 existing coping/adaptation to biophysical impact is not enough

2 measures have costs (including non-economic) that cannot be regained

3 despite short-term merits, measures have negative effects in the longer term (erosive coping)

4 no measures are adopted - or possible - at all.

In the North Bank Region of The Gambia, the first and third pathways were most common. Almost all households surveyed adopted one or several coping strategies to deal with impacts of the 2011 drought. However, in about two-thirds of the households, respondents reported that these measures were not enough to avert adverse effects. The main aim of the coping strategies was to obtain food when crop production failed because of drought. In approximately two-thirds of the households surveyed, the coping strategies were not enough to avoid reduced food intake. Rising food prices made it more difficult for households to cope. The study also found that many coping strategies adopted by households in the North Bank Region were erosive, as they compromised livelihood sustainability in the medium to long term. This was the case, for example, when productive assets (like farm implements and draught animals) were sold to buy food, and when people had to reduce expenses on school fees and health care.

To address loss and damage from drought in The Gambia, this paper puts forward the following recommendations:

- Most of the existing policies and interventions that aim to make rural households in The Gambia less vulnerable to drought impacts, such as the promotion of soil and water conservation techniques, promotion of vegetable cultivation in small irrigated gardens, and the introduction of drought-tolerant rice cultivars, are useful, but need to be improved and expanded to become more efficient and to reach all intended beneficiaries. In particular, more irrigation agriculture could help farmers in the region become less dependent on rainfall; and a more diverse crop mix, including tree crops and crops that do well under dry conditions could reduce the risk of crop failure. 
- Existing measures are mostly aimed at preventing crop failures. As noted, this is very useful, but the experience of the 2011 drought shows that more should be done to prevent loss and damage when droughts cause crops to fail. Measures other than providing food aid should be considered. The Gambia government could, for example, facilitate the introduction of an affordable crop insurance to offset crop losses when drought hits. The government and NGOs could further promote the non-farm sector in rural areas through skills development and better marketing of locally produced goods. When people have viable sources of non-farm income during the long dry season, when there is less work on their farms, this would greatly improve their capacity to cope with crop failures.

- It is still important to raise farmers' awareness and knowledge of climate variability and climate change and the implications for their livelihoods. One way to do this is through public broadcasting (such as radio and television). This goes beyond telling farmers what they do not yet know. It is also about reminding them of the drought risks. For example, every farmer in the Sahel Region knows that drought can hit at any time, and that it is important to store surplus harvest in good years to be better prepared for a bad harvest in a drought year. However, people need to be reminded of this from time to time to resist the temptation to sell surplus harvest in order to have money to spend on non-essential goods and services.

\section{References}

Birkmann, J. (2011) 'First- and second-order adaptation to natural hazards and extreme events in the context of climate change', Natural Hazards, Vol. 58, No. 2, pp.811-840.

Boubacar, I. (2013) 'Economic implications of climate change: evidence from agricultural productivity', International Journal of Global Warming.

Cessay, S., Gilbert, E., Mills, B., Rowe, J. and Norton, G.W. (1989) Analysis of Agricultural Research Priorities in the Gambia, Australian Centre for Integrated Agricultural Research, Canberra.

Dai, A., Lamb, P.J., Trenberth, K.E., Hulme, M., Jones, P.D. and Xie, P. (2004) 'The recent Sahel drought is real', International Journal of Climatology, Vol. 24, No. 11, pp.1323-1331.

Darboe, F. and Bojang, L. (2005) Assessment of Vulnerability to Climate Change in Fisheries and Proposals for Adaptation Measures, Banjul, Government of The Gambia.

Davies, S. (1996) Adaptable Livelihoods: Coping with Food Insecurity in the Malian Sahel, Macmillan. Press Ltd, London.

de Waal, A. (1989) 'Is famine relief irrelevant to rural people?', IDS Bulletin, Vol. 20, No. 2, pp.63-67.

Department of Agriculture (2005) Annual Agriculture Report, Department of Agriculture, Planning Unit, Banjul.

Devereux, S. (1993) 'Goats before ploughs: dilemmas of household response sequencing during food shortages', IDS Bulletin, Vol. 24, No. 4, pp.52-59.

Dietz, T., Ruben, R. and Verhagen, J. (2004) The Impact of Climate Change on Drylands with a Focus on West Africa, Kluwer, Dordrecht.

Gaye, I. (2004) Onset, Cessation and Length of Rainy Season in the Gambia, Department of Water Resources, The Gambia.

German Technical Assistance (GTZ) (1999) National Action Plan to Combat Desertification Livestock and Range Management, Department of Forestry, Banjul, Government of The Gambia. 
Gibba, P. (2002) The Impact of Accurate and Timely Issue of Climate Forecast and Agrometeorological Warnings on Policy and Decision-making, Department of Water Resources, Banjul, The Gambia.

Government of The Gambia (2009) Disaster Risk Reduction and Climate Change Adaptation Programme for The Gambia, National Disaster Management Agency Programme, Banjul.

Jallow, B.P., Toure, S., Barrow, M. and Mathieu, A.A. (1999) 'Coastal zone of The Gambia and the Abidjan region in Côte d'Ivoire: sea level rise vulnerability, response strategies, and adaptation options', Climate Research, Vol. 12, Nos. 2-3, pp.129-136.

Mortimore, M. (1989) Adapting to Drought: Farmers, Famines and Desertification in West Africa, University Press, Cambridge.

National Environment Agency (2004) Coastal Zone Management Handbook for The Gambia, Banjul, National Environment Agency.

Njie, M. (2007) The Gambia National Adaptation Programme of Action (NAPA) on Climate Change, Banjul, Government of The Gambia.

The Gambia Department of Water Resources (2003) Water Resources Survey of The Gambia, Banjul, Government of The Gambia.

van der Geest, K. (2004) 'We're Managing!' Climate Change and Livelihood Vulnerability in Northwest Ghana, African Studies Centre, Leiden.

van der Geest, K. and Dietz, T. (2004) 'A literature survey about risk and vulnerability in drylands, with a focus on the Sahel', in Dietz, T., Rueben R. and Verhagen J. (Eds.): The Impact of Climate Change on Drylands, Kluwer, Dordrecht, pp.117-146.

Warner, K. and van der Geest, K. (2013) 'Loss and damage from climate change: local-level evidence from nine vulnerable countries', International Journal of Global Warming.

Warner, K., van der Geest, K., Kreft, S., Huq, S., Harmeling, S., Koen, K. and de Sherbinin, A. (2012) Evidence from the Frontlines of Climate Change: Loss and Damage to Communities Despite Coping and Adaptation. Loss and Damage in Vulnerable Countries Initiative, Policy report No. 9. United Nations University Institute for Environment and Human Security, Bonn.

Zaal, F., Dietz, T., Brons, J., van der Geest, K. and Ofori Sarpong, E. (2004) 'Sahelian livelihoods on the rebound: a critical analysis of rainfall, drought index and yields in Sahelian agriculture', in Dietz, T., Ruben, R. and Verhagen, J. (Eds.): The Impact of Climate Change on Drylands, pp.61-78, Kluwer, Dordrecht. 